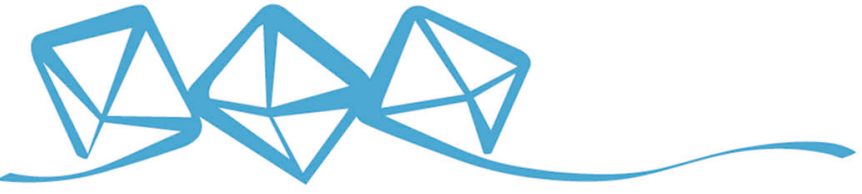 COMMUNICATIONS MATERIALS
}

ARTICLE

Check for updates https://doi.org/10.1038/s43246-020-00093-z OPEN

\section{Infrared response in photocatalytic polymeric carbon nitride for water splitting via an upconversion mechanism}

Zhengyuan Jin (1) 1,2,3, Xiantao Jiang ${ }^{2}$, Qitao Zhang ${ }^{2}$, Shaolong Huang ${ }^{1}$, Luhong Zhang ${ }^{1}$, Lili Huang ${ }^{3}$, Tingchao He', Han Zhang (1) ${ }^{2}$, Teruhisa Ohno ${ }^{4}$, Shuangchen Ruan ${ }^{1} \&$ Yu-Jia Zeng (i) ${ }^{1 凶}$

Broad-spectrum light activation in photocatalytic materials is considered vital for effective solar-to-hydrogen energy conversion. Here, we propose an upconversion process in oxygendoped polymeric carbon nitride $\left(\mathrm{C}_{3} \mathrm{~N}_{4}\right)$ nanosheets, resulting in high photocatalytic activity for hydrogen generation from water splitting under infrared light irradiation. Due to the upconversion, the photoexcited electrons are transferred to the conduction band, and a $\sigma^{\star}$ carbon-oxygen orbital localized on the triazine matrix ring resulting from oxygen doping extends the lifetime of photogenerated electrons, which increases the photocatalytic activity under both infrared and visible light. Our material exhibits high apparent quantum efficiency of $0.014 \%$ and $23 \%$ at $850 \mathrm{~nm}$ and $420 \mathrm{~nm}$, respectively. Under infrared light $(\lambda \geq 800 \mathrm{~nm}$, $24 \mathrm{~mW} \mathrm{~cm}^{-2}$ ), the hydrogen production rate of our material is $22.84 \mu \mathrm{mol} \mathrm{h}^{-1} \mathrm{~g}^{-1}$, which can reach a yield similar to that of pristine $\mathrm{C}_{3} \mathrm{~N}_{4}$ under visible light.

\footnotetext{
${ }^{1}$ Shenzhen Key Laboratory of Laser Engineering, College of Physics and Optoelectronic Engineering, Shenzhen University, Shenzhen 518060, P. R. China. 2 Shenzhen Engineering Laboratory of Phosphorene and Optoelectronics, International Collaborative Laboratory of 2D Materials for Optoelectronics Science and Technology, Shenzhen University, Shenzhen 518060, P. R. China. ${ }^{3} \mathrm{Ctr}$ Adv Mat Diagnost Technol, Shenzhen Technol University, Shenzhen 518118, P. R. China. ${ }^{4}$ Department of Applied Chemistry, Faculty of Engineering, Kyushu Institute of Technology, 1-1 Sensuicho, Tobata, Kitakyushu 804-8550, Japan.

凶email: yjzeng@szu.edu.cn
} 
$\mathrm{P}$ hotocatalysis is considered one of the most promising technologies for converting abundantly available solar energy into useful chemical energy. In particular, solardriven water splitting for $\mathrm{H}_{2}$ generation has attracted much attention because it is a sustainable strategy for producing renewable energy ${ }^{1,2}$. However, the low utilization efficiency for solar energy is still a bottleneck in photocatalysis because photocatalysts typically have a narrow absorption range. For example, $\mathrm{TiO}_{2}$, the most well-studied photocatalyst, can respond only to ultraviolet light $(5 \% \text { of total solar energy })^{3}$. The theoretical maximum efficiency for the water splitting reaction by a single photocatalyst increases with the wavelength; i.e., values of 2,16 , and $32 \%$ are obtained upon increasing the wavelength from UV to 400,600 , and $800 \mathrm{~nm}$, respectively ${ }^{4,5}$. Therefore, to improve the solar energy utilization efficiency, developing a photocatalyst with broad-spectrum responsiveness is one of the most effective strategies for solar-to-hydrogen energy conversion. Theoretically, the water splitting reaction can proceed only in a photocatalyst whose band gap straddles the reduction and oxidation potentials of water. It is, therefore, a great challenge to find a good material that simultaneously has a broad-spectrum response and suitable redox potentials. Neither new materials such as black phosphorus (phosphene) nor $\mathrm{TiO}_{2-\mathrm{x}}$ obtained from band gap engineering has achieved the desired photocatalytic activity due to the low redox capacity of these materials ${ }^{6,7}$.

We propose a different strategy to design infrared lightresponsive photocatalysts. The strategy is based on a single photocatalyst in which the infrared light response is achieved by an upconversion process and high activity is guaranteed by the prolonged lifetime of the photoexcited carriers achieved by the introduction of a new energy level in conduction band. Polymeric carbon nitride $\left(\mathrm{C}_{3} \mathrm{~N}_{4}\right)$ has been one of the most popular materials in photocatalysis in the past decade since its discovery as a visible light-responsive photocatalyst in $2009^{8}$. However, $\mathrm{C}_{3} \mathrm{~N}_{4}$ has never been applied as an infrared light-responsive material or an upconversion material, despite very limited reports on its upconversion properties, which have been ascribed to the quantum size effect ${ }^{9,10}$. Herein, we demonstrate that upconversion, which we believe is an important but overlooked process, is an "intrinsic" process even in bulk $\mathrm{C}_{3} \mathrm{~N}_{4}(\mathrm{PCN})$.

In this work, when the weight ratio of melamine to cyanuric acid reaches $M / C \leq 1 / 3$, we obtain a carbon nitride in the form of porous nanosheets, in which $\mathrm{O}$ is doped at the position of the triazine matrix ring to form a new energy level in conduction band. We find the energy level provided by $\sigma^{*}{ }_{\mathrm{C}-\mathrm{O}}$ in the conduction band, which is beneficial for prolonging the life time of photogenerated electrons. Moreover, $\sigma^{*}{ }_{\mathrm{C}-\mathrm{O}}$ is next to $\pi^{*}{ }_{\mathrm{C}=\mathrm{N}-\mathrm{C}}$, which makes the electrons easy to be photogenerated to the level even by infrared light (two-photon absorption). Therefore, our carbon nitride not only generates $\mathrm{H}_{2}$ from water splitting under infrared light irradiation, but also the $\mathrm{H}_{2}$ generation rate of MCN1-4 under visible light irradiation is 85.7 times higher than that of PCN.

\section{Results}

Characterization of PCN and MCN1-4. The texture, structure, and morphology of the samples were investigated by scanning electron microscopy (SEM), transmission electron microscopy (TEM) and atomic force microscopy (AFM). PCN shows large particles with a stacked sheet structure (Fig. 1a, b). On the other hand, MCN1-4 shows a translucent thin layer morphology with a porous surface and folded edges (Fig. 1c, d). As shown in the AFM image (Fig. 1e), the nanosheets of MCN1-4 have an average thickness of approximately $3.5 \mathrm{~nm}$ and an average planar area of $\sim 18 \mu^{2}$. MCN1-4 has a Brunauer-Emmett-Teller (BET) specific surface area of $150.0 \mathrm{~m}^{2} \mathrm{~g}^{-1}$, which is 14 times higher than that of PCN $\left(11.3 \mathrm{~m}^{2} \mathrm{~g}^{-1}\right)$, indicating that most MCN1-4 samples exhibit an ultra-thin nanosheet morphology (see Supplementary Table 1). The total Barrett-Joyner-Halenda (BJH) pore volume of MCN1-4 is up to $0.79 \mathrm{~cm}^{3} \mathrm{~g}^{-1}$, which is almost 8 times higher than that of PCN $\left(0.10 \mathrm{~cm}^{3} \mathrm{~g}^{-1}\right)$. Notably, MCN1-4 has a microporous structure $\left(0.02 \mathrm{~cm}^{3} \mathrm{~g}^{-1}\right)$, which not only provides a number of reaction sites, but also decreases the charge transfer distance and thus effectively increases the photocatalytic activity (see Supplementary Fig. 6c)

Figure 2a shows X-ray diffraction (XRD) patterns of PCN and MCN1-4 samples. PCN has two peaks at 13.1 degrees and 27.6 degrees, which are assigned to in-plane repeating units (100) of the tri-s-triazine matrix and the interlayer distances of parallel conjugated aromatics (002), respectively ${ }^{11}$. The characteristic peaks of MCN1-4 are located at 13.1 degrees and 27.8 degrees, indicating that MCN1-4 has the same structure as PCN. The most intense peak of MCN1-4 shifts slightly to 27.8 degrees, suggesting that MCN1-4 has a shorter stacking interlayer distance $(0.3206$ $\mathrm{nm})$ than does PCN $(0.3232 \mathrm{~nm})$. Simultaneously, the peak at 27.8 degrees becomes less pronounced, indicating that the number of layers in the structure is reduced to form a thinner structure $^{12}$, which agrees with the morphology results presented in Fig. 1. Both the reduction in the interlayer distance and the nanosheet morphology are beneficial to increasing the lifetime of photoexcited carriers to enhance photocatalytic activity.

To further identify the functional groups of molecules, Fourier transform infrared (FT-IR) spectroscopy was employed (Fig. 2b). Both samples give rise to a peak characteristic of the tri-s-triazine ring mode at approximately $806.1 \mathrm{~cm}^{-1}$. The MCN1-4 spectrum presents several new peaks from 1238 and $1070 \mathrm{~cm}^{-1}$, which are assigned to stretching vibrations of the $\mathrm{C}-\mathrm{O}-\mathrm{C}$ group ${ }^{13,14}$. The bands between 1700 and $1200 \mathrm{~cm}^{-1}$ are attributed to the skeletal stretching vibration of aromatic $\mathrm{C}-\mathrm{N}$ heterocycles. These peaks in the spectrum of MCN1-4 shift to lower wavenumbers than those of $\mathrm{PCN}$, which may be due to the presence of a $\mathrm{C}-\mathrm{O}-\mathrm{C}$ moiety. No significant changes are detected in the peaks at $3100-3300 \mathrm{~cm}^{-1}$ (see Supplementary Fig. $7 \mathrm{~b}$ ), which correspond to $-\mathrm{NHx}$ moieties. The FT-IR results confirm the $\mathrm{O}$ doping in the $\mathrm{C}_{3} \mathrm{~N}_{4}$.

To further elucidate the $\mathrm{O}$ doping position, the chemical states of elements were studied by X-ray photoelectron spectroscopy (XPS). As shown in the XPS survey spectra (see Supplementary Fig. 8), MCN1-4 is composed of $\mathrm{C}, \mathrm{N}$, and $\mathrm{O}$, similar to PCN. The C1s XPS spectrum of PCN shows two fitting peaks at 284.6 and $288.0 \mathrm{eV}$, corresponding to the $\mathrm{C}-\mathrm{C}$ and $\mathrm{N}=\mathrm{C}-\mathrm{N}$ bonds (Fig. $2 \mathrm{c}$ ). The spectrum of MCN1-4 shows three fitting peaks, including a new peak at $286.2 \mathrm{eV}$ attributed to the $\mathrm{C}-\mathrm{O}$ bond ${ }^{13}$. Figure $2 \mathrm{~d}$ shows the O1s XPS spectra of the samples. The spectra of both samples show a peak at $532.0 \mathrm{eV}$, which is ascribed to chemisorbed oxygen $\left(\mathrm{H}_{2} \mathrm{O}\right)$. Note that the spectrum of MCN14 has a new peak at approximately $533.2 \mathrm{eV}$, which is attributed to the $\mathrm{C}-\mathrm{O}-\mathrm{C}$ moiety ${ }^{14}$. In the $\mathrm{C}_{3} \mathrm{~N}_{4}$ structure, $\mathrm{C}-\mathrm{O}-\mathrm{C}$ may exist in two positions: at the linker position $\mathrm{N}_{(-\mathrm{NHx})}$ and at the triazine

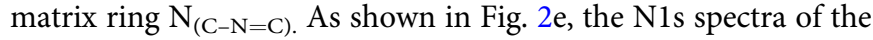
two samples exhibit three fitted peaks at 398.5, 399.6, and $401.0 \mathrm{eV}$, which are attributed to $\mathrm{C}=\mathrm{N}-\mathrm{C}, \mathrm{N}-(\mathrm{C})_{3}$ and $\mathrm{C}-\mathrm{NHx}$, respectively. For $\mathrm{PCN}$, the ratios of the $\mathrm{N}_{(\mathrm{C}=\mathrm{N}-\mathrm{C})}, \mathrm{N} 2_{(\mathrm{N}-\mathrm{C} 3)}$ and $\mathrm{N} 3_{(-\mathrm{NHx})}$ peaks are $66 \%, 28 \%$, and $6 \%$, respectively, but the ratios of these three peaks in MCN1-4 are 59\%, 32\%, and 9\% (see Supplementary Tables 4-6) ${ }^{15}$. Only the ratio of $\mathrm{N} 1(\mathrm{C}=\mathrm{N}-\mathrm{C})$ decreased, indicating that the $\mathrm{O}$ atom of $\mathrm{C}-\mathrm{O}-\mathrm{C}$ is located at the $\mathrm{N}$ position of the triazine matrix ring in MCN1-4.

The results of elemental analysis (EA) and XPS elemental analysis (XPS-EA) are shown in Supplementary Tables 2 and 3 and illustrate the distribution of the elements. The surface $\mathrm{O}$ ratio of MCN1-4 is $28 \%$ and $9 \%$ higher than that of PCN, as seen from 

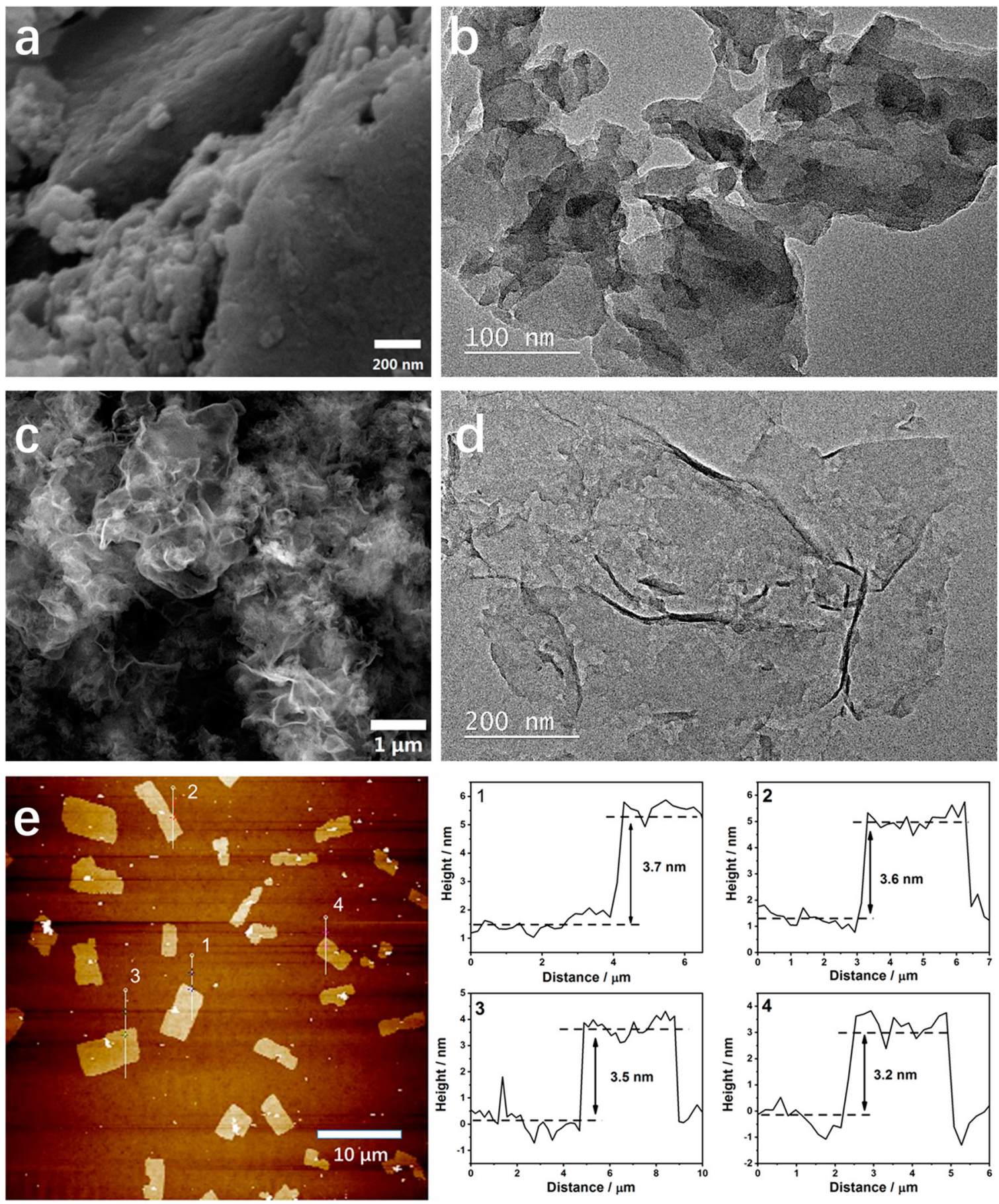

Fig. 1 Structure of PCN and MCN1-4. a, c SEM images of PCN and MCN1-4; b, d TEM images of PCN and MCN1-4; e AFM image and the corresponding height profiles of MCN1-4.

the XPS-EA and EA results, respectively; these results indicate that $\mathrm{C}-\mathrm{O}-\mathrm{C}$ is mainly distributed on the surface of MCN1-4, since XPS is more surface sensitive. Compared with the surface $\mathrm{C} /$ $\mathrm{N}$ ratio of PCN, that of MCN1-4 increases, but the overall $\mathrm{C} / \mathrm{N}$ ratio decreases. The results show that the $\mathrm{C}$ content gradually increases from the inside to the surface of MCN1-4 $4^{16}$, which is beneficial for charge transfer from the inside to the surface.

Electron paramagnetic resonance (EPR) spectra of the samples are shown in Fig. 2f. The spectra of both samples exhibit an isotropic singlet with a Lorentzian line shape at $g=2.0042$, which is assigned to the lone pair electrons of the sp2-hybridized carbons in the $\pi$-bonded aromatic rings ${ }^{17}$. The peak intensity of
MCN1-4 is lower than that of PCN, indicating a decrease in the unpaired electron density. This finding is probably due to the replacement of $\mathrm{N}$ with $\mathrm{O}$ on the triazine matrix ring, which partially destroys the $\pi$ bonding structure of the entire ring.

Solid-state NMR (nuclear magnetic resonance) was used to verify the structure of the surface species (Fig. 3a, b). For PCN, the ${ }^{13} \mathrm{C}$ magic-angle spinning (MAS) NMR spectrum shows two peaks at 156.7 and $164.7 \mathrm{ppm}$, which can be assigned to $(\mathrm{C})_{3} \mathrm{~N}$ and $(\mathrm{C})_{2} \mathrm{~N}-\mathrm{NHx}^{18}$; the $1 \mathrm{H}$ MAS NMR spectrum shows two peaks at 4.5 and $9.6 \mathrm{ppm}^{19,20}$, which can be ascribed to $\mathrm{R}-\mathrm{NH}_{2}$ and R-NH-R, respectively. MCN1-4 presents new peaks at 163.3 and $3.4 \mathrm{ppm}$ in the ${ }^{13} \mathrm{C}$ and ${ }^{1} \mathrm{H}$ MAS NMR spectra, respectively, 

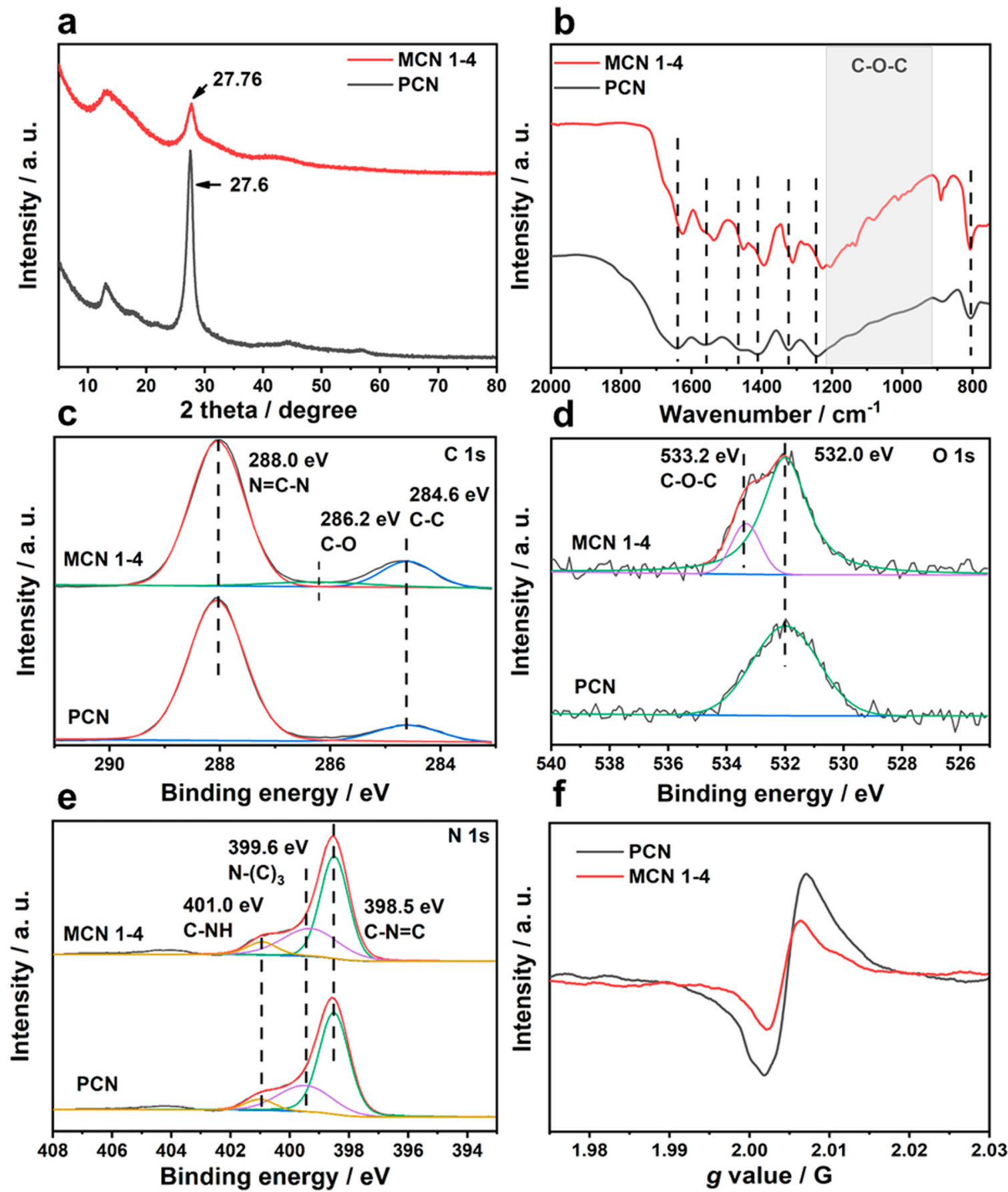

Fig. 2 XRD, FT-IR, and EPR characterization of PCN and MCN1-4. a XRD patterns, b FT-IR spectra, c C1s XPS spectra, d O1s XPS spectra, e N1s XPS spectra, and $\mathbf{f}$ in situ EPR signals of PCN and MCN1-4.

in addition to the peaks at the same positions as those for PCN. The peaks at $163.3 \mathrm{ppm}$ and $3.4 \mathrm{ppm}$ are attributed to $-\mathrm{O}-\mathrm{CN}$ and $-\mathrm{CH}-\mathrm{O}-$ (according to the database "Chem 605 " provided by Hans J. Reich, University of Wisconsin.), respectively, indicating the presence of $\mathrm{C}-\mathrm{O}-\mathrm{C}$ in the triazine matrix ring of $\mathrm{MCN} 1-4$ (inset of Fig. 3b). Since the oxygen in $\mathrm{C}-\mathrm{O}-\mathrm{C}$ has two lone pairs of electrons, the other peaks shift downfield, which is consistent with the EPR results.

A schematic illustration of the formation of O-doped porous nanosheet carbon nitride is shown in Fig. 3c. Hydrothermal treatment of the appropriate weight ratio of melamine and cyanuric acid results in $\mathrm{O}$ doping in the triazine matrix ring to replace $\mathrm{N}_{(\mathrm{C}-\mathrm{N}=\mathrm{C})}$. Moreover, we find that the $\mathrm{M} / \mathrm{C}$ weight ratio of
$1 / 3$ is the key point, as shown in Supplementary Fig. 13. Because a melamine molecule can form hydrogen bonds with three cyanuric acids ${ }^{21,22}$, when melamine is surrounded by cyanuric acid, spatial distance will exist between melamine molecules, which results in the formation of the O-doped porous nanosheet morphology.

Photocatalytic activities. Figure 4a shows the time course of $\mathrm{H}_{2}$ generation from water splitting under infrared light $(\lambda \geq 800 \mathrm{~nm})$ irradiation. $\mathrm{PCN}$ catalyses no $\mathrm{H}_{2}$ production, whereas MCN1-4 generates $4.27 \mu \mathrm{mol}$ of $\mathrm{H}_{2}$ after $4 \mathrm{~h}$ of irradiation (generation rate of $22.84 \mu \mathrm{mol} \mathrm{h}^{-1} \mathrm{~g}^{-1}$ ). Considering that the intensity of infrared light is only $24.4 \mathrm{~mW} \mathrm{~cm}^{-2}$, the photocatalytic activity of MCN14 exhibits even higher under $100 \mathrm{~mW} \mathrm{~cm}^{-2}$ of infrared light than 
a

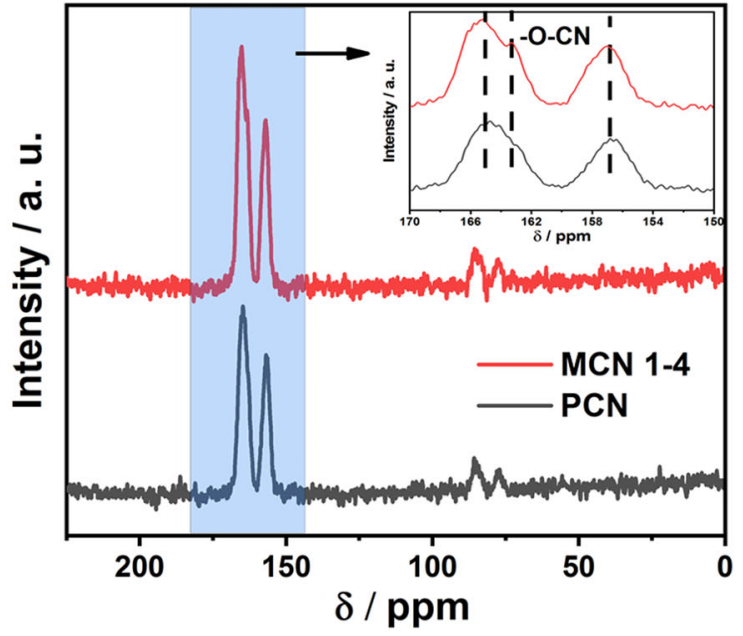

b

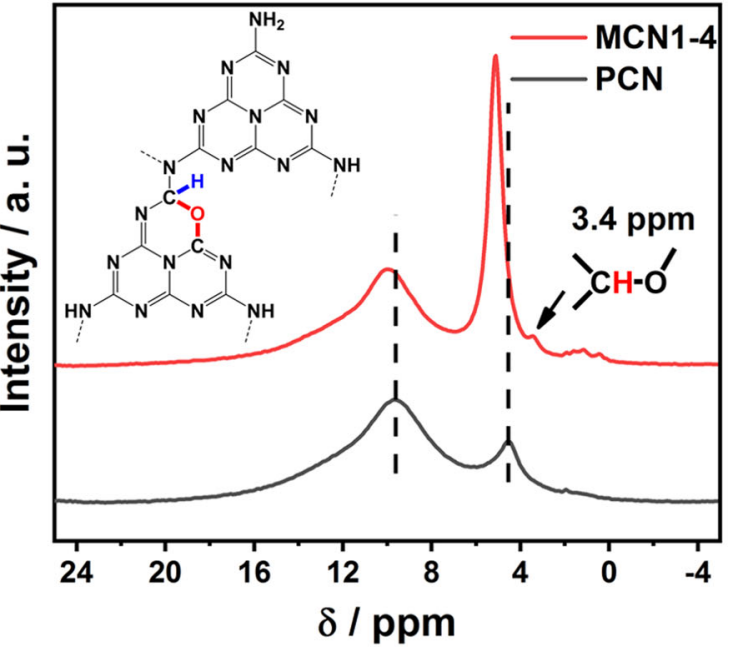

C

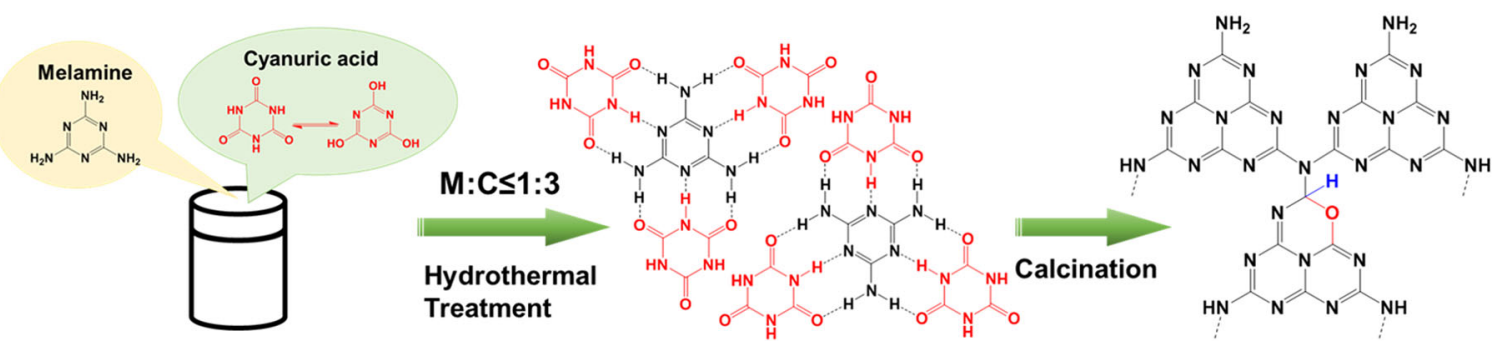

Fig. 3 NMR characterization and fabrication process of MCN1-4. $\mathbf{a}^{13} \mathrm{C}$ and $\mathbf{b}{ }^{1} \mathrm{H}$ NMR solid-state spectra of PCN and MCN1-4. $\mathbf{c}$ Schematic illustration of the formation of O-doped two-dimensional carbon nitride.

that of PCN under visible light $\left(37.09 \mu \mathrm{mol} \mathrm{h}{ }^{-1} \mathrm{~g}^{-1}\right)$ as shown in Supplementary Fig. 14.

Figure $4 \mathrm{~b}$ shows the photoluminescence (PL) spectra of PCN and MCN1-4 upon excitation at $800 \mathrm{~nm}$. The PL spectra of both samples show a peak in the blue region (450-500 nm), indicating that the samples have upconversion properties ${ }^{23}$. The PL spectra together with time-resolved fluorescence decay spectra are used to evaluate the charge separation dynamics of the samples. PCN gives rise to a peak centred at $468 \mathrm{~nm}$, and MCN1-4 gives rise to a peak centred at $496 \mathrm{~nm}$. The peak intensity in the spectrum of MCN1-4 is lower than that in the spectrum of PCN, demonstrating that MCN1-4 has a lower recombination rate of photoexcited carriers. Furthermore, MCN1-4 has a much longer average lifetime of $7.63 \mathrm{~ns}$ than does $\mathrm{PCN}$, with an average lifetime of $4.41 \mathrm{~ns}$ (see Supplementary Fig. 15 and Supplementary Table 7). In the case of PCN, the short average lifetime of $4.41 \mathrm{~ns}$ and the stacked sheet structure prevent the photoexcited carrier from being transferred from the interior of the material to the reaction site on the surface. Therefore, although electrons are photoexcited to the conduction band of PCN, the lifetime of the excited state is too short for water splitting to proceed. In contrast, MCN1-4 exhibits a long lifetime of 7.63 ns (almost the same as the average lifetime at $365 \mathrm{~nm}$ ) and a porous nanosheet $(3.5 \mathrm{~nm})$ structure; thus, photoexcited electrons have a sufficient lifetime for water splitting. As shown in Fig. 4c, when PCN is excited with an $800 \mathrm{~nm}$ laser, white light can be clearly observed from the material even at a laser pump power of $\sim 100 \mathrm{~mW} \mathrm{~cm}^{-2}$. On the other hand, little light can be observed from MCN1-4 under the same condition, which is consistent with the results of PL. Nonlinear optical characteristics can be found from the intensity-dependent fluorescence spectra of MCN1-4 excited at
$800 \mathrm{~nm}$. Moreover, it is found that the hydrogen generation rate is proportional to the irradiation intensity (slope $=1.77$ ), thus confirming the existence of two-photon absorption (2PA) mechanism at inferred light $(\lambda \geq 800 \mathrm{~nm}$, see Supplementary Fig. 16). The nonlinear absorption coefficients (two-photon absorption coefficient) of PCN and MCN1-4 are $0.9696 \times 10^{-2}$ $\mathrm{cm} \mathrm{GW}-1$ and $6.26 \times 10^{-2} \mathrm{~cm} \mathrm{GW}^{-1}$, respectively, which are calculated from the results of open-aperture Z-scan under $800 \mathrm{~nm}$ excitation (see Supplementary Fig. 17) ${ }^{24}$.

The photocatalytic activities under visible light were measured by in situ $\mathrm{H}_{2}$ generation from water splitting. After $6 \mathrm{~h}$ of irradiation under visible light $(\lambda \geq 420 \mathrm{~nm}), \mathrm{MCN} 1-4$ generates $179.44 \mu \mathrm{mol}$ of $\mathrm{H}_{2}$, while PCN generates $1.61 \mu \mathrm{mol}$ (Fig. $4 \mathrm{~d}$ ). Part of the photoexcited electrons are used to reduce the $\mathrm{Pt}^{4+}$ available at the beginning of the experiment, resulting in a decrease in the hydrogen production ${ }^{25}$. Thus, the average $\mathrm{H}_{2}$ generation rate is calculated between 3 and $6 \mathrm{~h}$, during which time the hydrogen production rate tends to be stable. The average $\mathrm{H}_{2}$ generation rates of MCN1-4 and PCN are $31.79 \mu \mathrm{mol} \mathrm{h}-1$ and $0.37 \mu \mathrm{mol} \mathrm{h} \mathrm{h}^{-1}$, respectively; i.e., the value for $\mathrm{MCN} 1-4$ is 85.7 times higher than that for PCN (Fig. 4h).

Figure 4e shows the PL spectra of PCN and MCN1-4 upon excitation at $365 \mathrm{~nm}$, which are similar to those obtained upon $800 \mathrm{~nm}$ excitation. The PL peak intensity of MCN1-4 is lower than that of PCN, and the average lifetime of MCN1-4 (7.84 ns) is longer than that of $\mathrm{PCN}(6.83 \mathrm{~ns})$, confirming the lower recombination rate of photoexcited carriers in MCN1-4 than in PCN (see Supplementary Fig. 15 and Supplementary Table 8). On the other hand, the PL peaks in the PCN spectrum are at the same position after excitation at both 365 and $800 \mathrm{~nm}$. However, the MCN1-4 spectrum shows three distinct peaks with different 


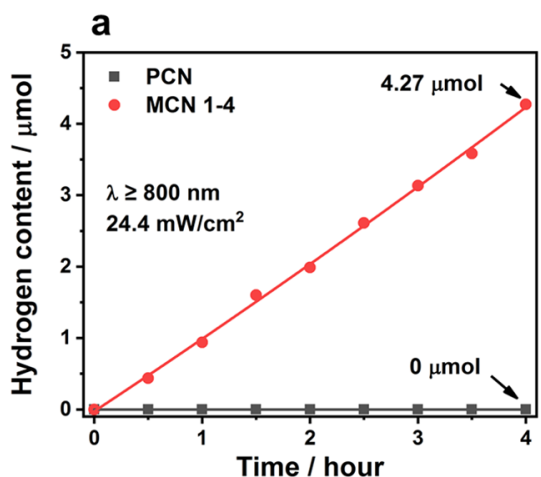

b

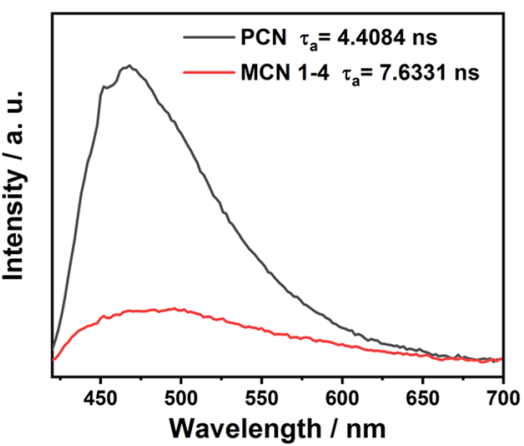

e
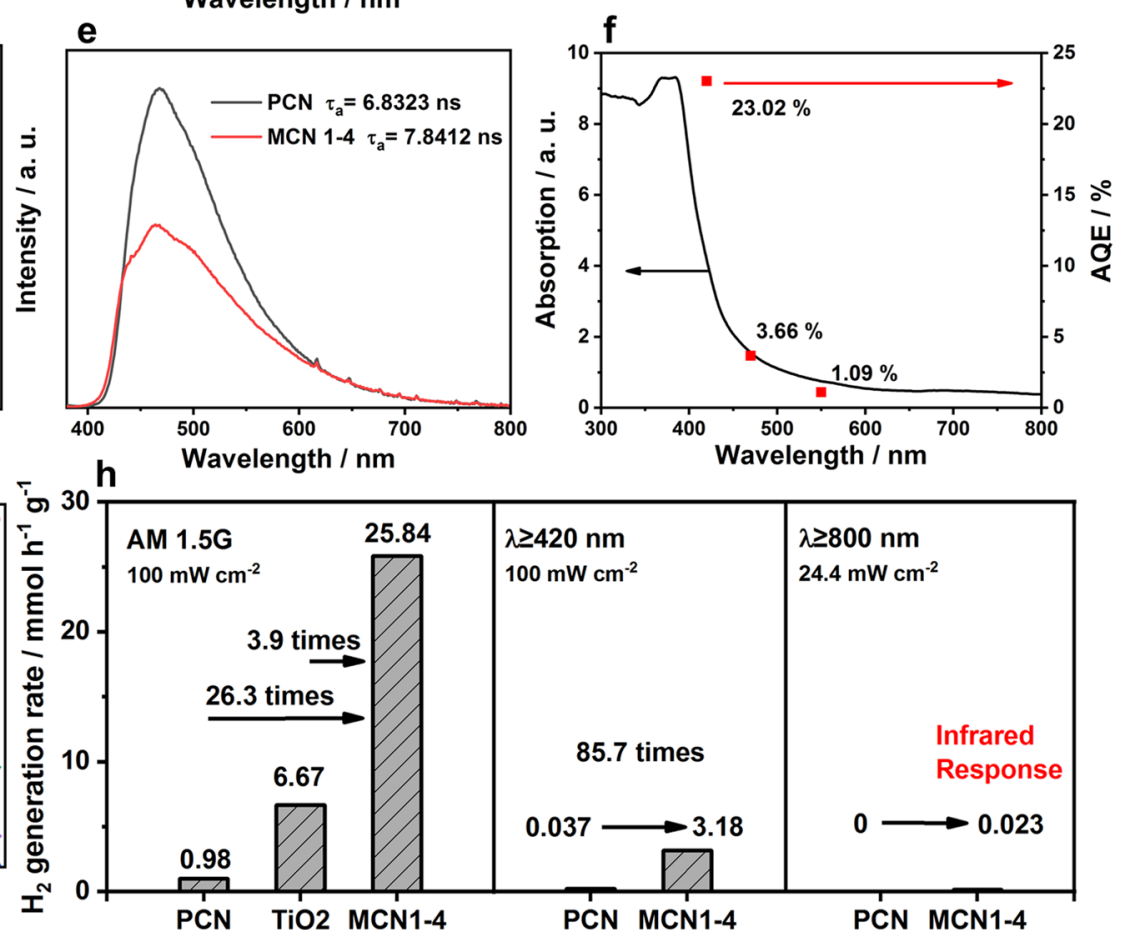

C
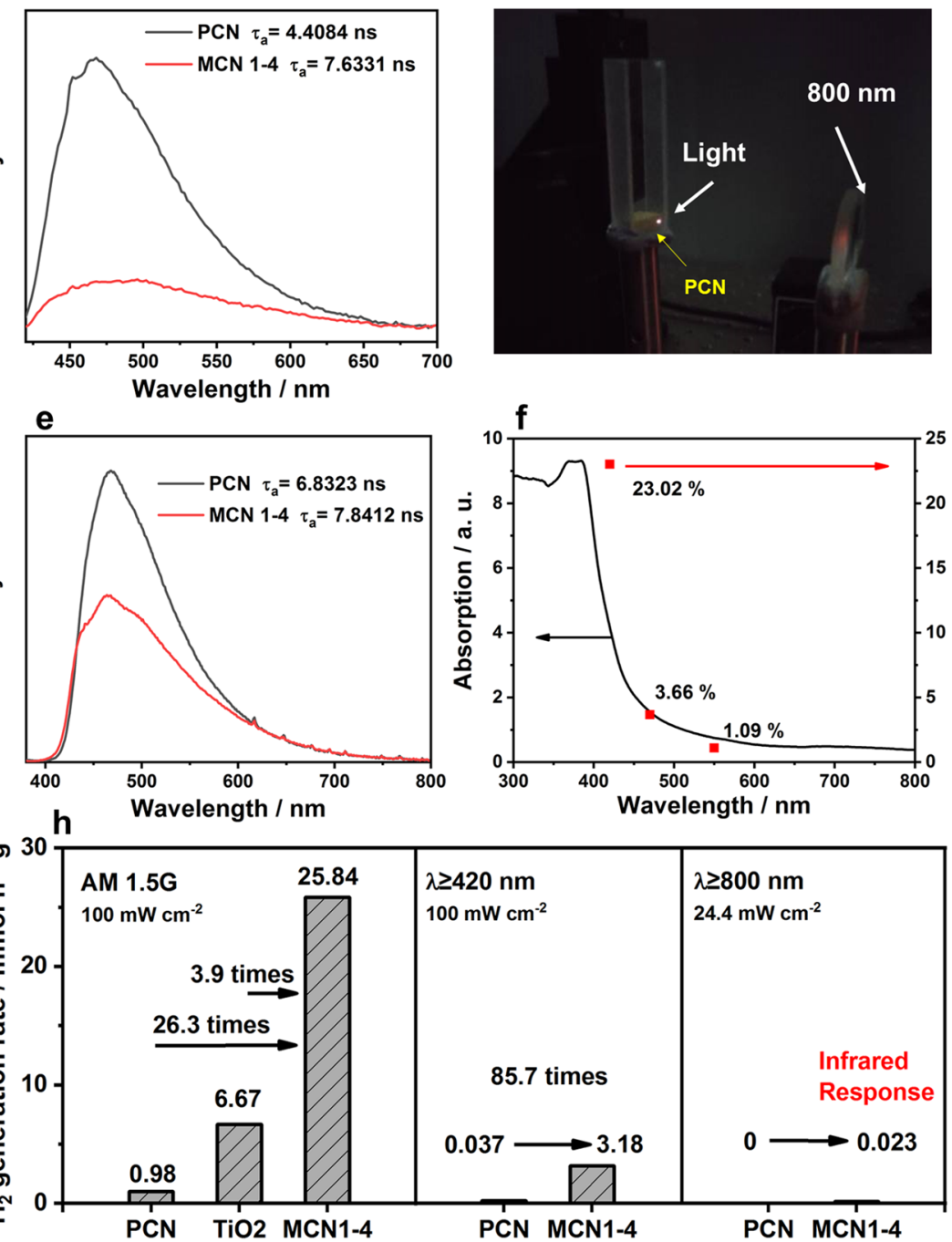

Fig. 4 Photocatalytic $\mathbf{H}_{\mathbf{2}}$ production performance over the samples under irradiation of various light source and characterization of PL. a Time course of $\mathrm{H}_{2}$ generation from water splitting under infrared light $(\lambda \geq 800 \mathrm{~nm})$ irradiation, $\mathbf{b}$ steady-state PL spectra with $800 \mathrm{~nm}$ excitation, $\mathbf{c}$ digital photograph of light emission from PCN under $800 \mathrm{~nm}$ laser excitation, $\mathbf{d}$ time course of $\mathrm{H}_{2}$ generation from in situ water splitting under visible light ( $\lambda \geq 420 \mathrm{~nm}$ ) irradiation, e steady-state PL spectra upon $365 \mathrm{~nm}$ excitation, $\mathbf{f}$ AQE against the light absorption wavelength of the $\mathrm{H}_{2}$ generation rate of MCN1-4, $\mathbf{g}$ time course of $\mathrm{H}_{2}$ generation from in situ water splitting under $\mathrm{AM} 1.5$ irradiation, $\mathbf{h}$ the $\mathrm{H}_{2}$ generation rate of samples at different light sources irradiation.

excitation wavelengths, indicating that MCN1-4 has a more complex band structure (see Supplementary Fig. 18), which will be discussed in the next section.

$\mathrm{AQE}$ is one of the most important parameters used to compare the photocatalytic activities of different materials ${ }^{26}$. MCN1-4 presents an AQE of $23.02 \%$ under monochromatic $420 \mathrm{~nm}$ light irradiation, which is one of the highest recorded values for $\mathrm{C}_{3} \mathrm{~N}_{4}$. In addition, MCN1-4 still has AQEs of 3.66\% and $1.09 \%$ under monochromatic $470 \mathrm{~nm}$ and $550 \mathrm{~nm}$ light irradiation, respectively, indicating that this material has a broad photoresponse. (see Supplementary Fig. 19).

Figure $4 \mathrm{~g}$ shows the time course of $\mathrm{H}_{2}$ generation from water splitting under AM 1.5 G irradiation. Although TEOA is unstable and generate $\mathrm{H}_{2}$ under ultraviolet light irradiation, it can be ignored because the yield of $\mathrm{H}_{2}$ is very low $(4.9 \mu \mathrm{mol}$ in $6 \mathrm{~h})$. Under the AM1.5 G irradiation, the $\mathrm{H}_{2}$ generation rate of MCN14 is $25.84 \mathrm{mmol} \mathrm{h}^{-1} \mathrm{~g}^{-1}$, which is four times higher than that of $\mathrm{TiO}_{2}$ (P25), becoming the first carbon nitride material to surpass P25 and also becomes the full spectrum response carbon nitride without hybridization (Fig. $4 \mathrm{~h})^{27}$.
The stability of MCN1-4 was measured by photocatalytic reaction over $36 \mathrm{~h}$ of visible light irradiation (see Supplementary Fig. 20). During visible light irradiation, the photocatalytic activity hardly changes in the first $18 \mathrm{~h}$. The activity decreases by $\sim 8 \%$ in the third cycle $(24-30 \mathrm{~h})$. After adding $5 \mathrm{ml}$ of triethanolamine (TEOA), the activity is slightly higher than that in the first cycle $(0-6 \mathrm{~h})$. This change in activity is mainly due to a change in the $\mathrm{pH}$ of the solution because TEOA is an alkaline substance. The recovery of activity indicates that MCN1-4 has good stability.

To understand the band structures of the materials, we performed UV-visible diffuse-reflectance spectroscopy (UV-vis DRS), valence band XPS (VB-XPS) and transient absorption spectroscopy (TAS). Figure 5a and Supplementary Fig. 21 show the UV-vis DRS results of the samples. The wavelength of maximum absorbance $\left(\lambda_{\max }\right)$ of MCN1-4 is located at approximately $385 \mathrm{~nm}$, which is blue-shifted slightly with respect to that of PCN at $\sim 387 \mathrm{~nm}$ due to the quantum confinement effect caused by the morphology of the nanosheets. MCN1-4 absorbs from approximately $478 \mathrm{~nm}$ to $800 \mathrm{~nm}$, which may originate from 

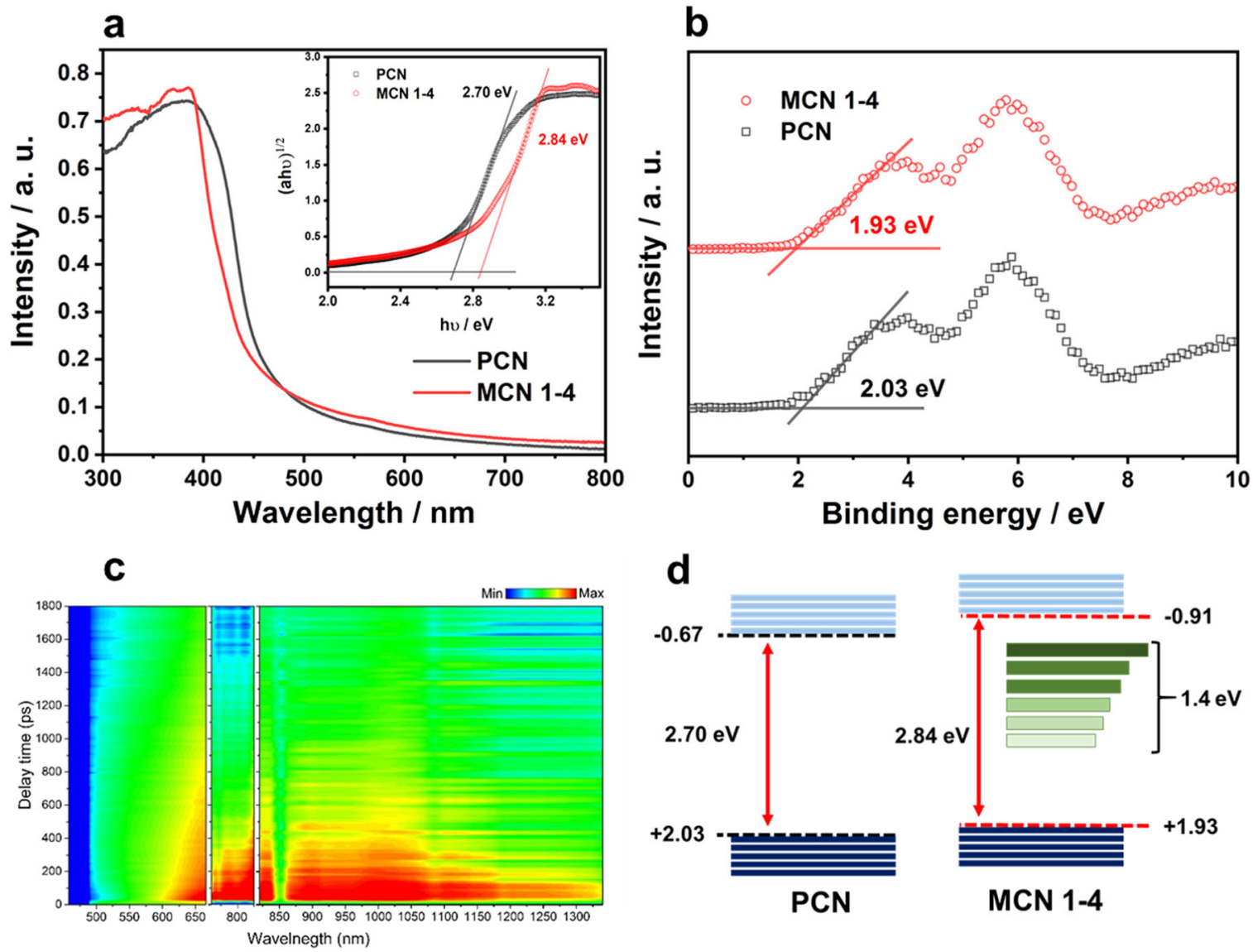

Fig. 5 UV-Vis DRS and bandgap state of PCN and MCN1-4. a UV-Vis DRS of PCN and MCN1-4 (the inset shows Tauc plots of samples), b VB-XPS spectra, c experimental TAS map of MCN1-4, d schematic band structure evolution of MCN1-4 compared with PCN.

charge transfer of the $n-\pi^{*}$ lone electron pairs of the $\mathrm{O}$ atom in the $\mathrm{C}-\mathrm{O}-\mathrm{C}$ moiety of the heptazine ring ${ }^{28}$. Therefore, the energy gaps of PCN and MCN1-4 are 2.70 and $2.84 \mathrm{eV}$, respectively, according to the Kubelka-Munk equation and Tauc plot method. As seen from the VB-XPS results, the valence bands of PCN and MCN1-4 are located at 2.03 and $1.93 \mathrm{eV}$, respectively.

As determined by the TAS analysis, the actual band structure of MCN1-4 is rather complex, especially the intermediate bands. A large signal can be detected from 486 to $1081 \mathrm{~nm}(2.55 \mathrm{eV}$ to $1.15 \mathrm{eV}$ ) in the MCN1-4 spectrum (Fig. 5c, d and see Supplementary Fig. 23), probably originating from the intermediate bands caused by the defects ${ }^{29-31}$. Supplementary Fig. 23 shows the kinetics and spectral properties at different wavelengths. In the ranges of $760-820 \mathrm{~nm}$ and $810-1350 \mathrm{~nm}$, there are many intermediate bands with lifetimes of longer than $2 \mathrm{~ns}$, indicating the presence of long-wavelength $(\lambda \geq 760 \mathrm{~nm})$ sustained photoexcited electron bands (see Supplementary Fig. 24). The electrons in these bands have a sufficiently long lifetime to absorb another photon for the second excitation (Fig. 5d). For instance, in the case of $800 \mathrm{~nm}$ irradiation, the electrons are excited to the intermediate bands by absorbing the energy of one photon, and then the electrons absorb energy from another photon to be excited to the conduction band. We speculate based on the TAS results that MCN1-4 may respond to $1325 \mathrm{~nm}$ light by multiphoton absorption (see Supplementary Fig. $23 \mathrm{~h})^{32}$.

To further investigate the O-binding form, the local electronic configuration, and the chemical structure of MCN1-4, near-edge $\mathrm{X}$-ray absorption fine structure (NEXAFS) analysis was used. In the nitrogen K-edge region (Fig. 6a), three main characteristic resonances are observed at $399.6,401.7$, and $402.5 \mathrm{eV}$, which correspond to the $\pi^{*} \mathrm{C}=\mathrm{N}-\mathrm{C}$ orbitals localized on aromatic nitrogen atoms, the $\pi^{*}{ }_{\mathrm{N}-3 \mathrm{C}}$ orbitals on graphitic threecoordinate nitrogen atoms, and the $\pi^{*}{ }_{\mathrm{N}-\mathrm{C}}$ orbitals of sp3hybridized $\mathrm{N}-\mathrm{C}$ bridging groups within the tri-s-triazine moieties, respectively. The characteristic peaks of MCN1-4 in the nitrogen K-edge region are unchanged compare to that of $\mathrm{PCN}$, indicating that $\mathrm{O}$ is doped by substituting for the $\mathrm{N}$ in MCN1-4. Figure 6b shows the carbon K-edge NEXAFS spectra of PCN and MCN1-4. Both spectra have peaks at 285.7 and 288.7 $\mathrm{eV}$, which are attributed to $\pi^{*}$ graphite and $\pi^{*} \mathrm{C}=\mathrm{N}-\mathrm{C}$ orbitals, respectively 33,34 . The $\pi_{\text {graphite }}^{*}$ and $\pi^{*} \mathrm{C}=\mathrm{N}-\mathrm{C}$ intensities of MCN14 are both lower than those of $\mathrm{PCN}$, indicating that the interlayer $\pi$ bond in MCN1-4 is stronger than that in PCN and that MCN14 has a thinner morphology than PCN. MCN1-4 has a new peak at $289.1 \mathrm{eV}$, which is attributed to $\sigma^{*} \mathrm{C}-\mathrm{O}$ of the $\mathrm{C}-\mathrm{O}-\mathrm{C}$ moiety in the triazine matrix ring ${ }^{35}$. The $\sigma^{*}{ }_{\mathrm{C}-\mathrm{O}}(289.1 \mathrm{eV})$ orbital energy is $0.4 \mathrm{eV}$ higher than that of $\pi^{*} \mathrm{C}=\mathrm{N}-\mathrm{C}(288.7 \mathrm{eV})$ in MCN1-4, which means that the energy level of $\sigma^{*} \mathrm{C}-\mathrm{O}$ is higher than the conduction band minimum ${ }^{36}$. The electrons photoexcited to the $\sigma^{*}$ C-O energy level have a longer lifetime, which can be confirmed from the time-resolved PL spectrum, see Supplementary Table 7 and 8. MCN1-4 with a $\sigma^{*}{ }_{\mathrm{C}-\mathrm{O}}$ level has a lifetime of $\tau 2=10.36 \mathrm{~ns}$, which is almost two times that of PCN without a $\sigma^{*}{ }_{\mathrm{C}-\mathrm{O}}$ level $(\tau 2=5.52 \mathrm{~ns})$. Furthermore, under $365 \mathrm{~nm}$ excitation, the lifetime $\tau 2=9.71 \mathrm{~ns}$ for MCN1-4 is longer than that for PCN $(\tau 2=8.86 \mathrm{~ns})$.

As shown in Supplementary Fig. 25, the crystal structure of MCN1-4 wrinkles by the $\mathrm{O}$ doping in the matrix ring, and no extra internal bands can be found from the results of calculation. Figure $7 \mathrm{a}$ shows total density of states (TDOS) and partially 
a

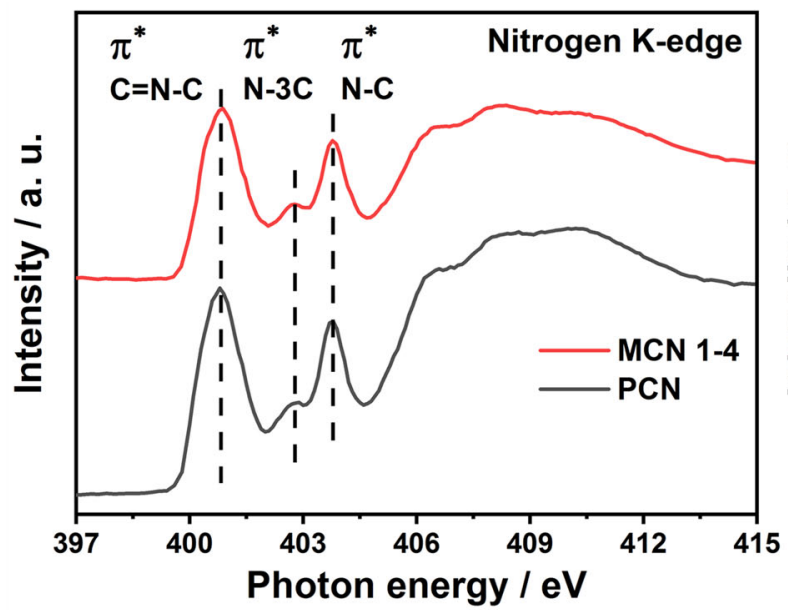

C b

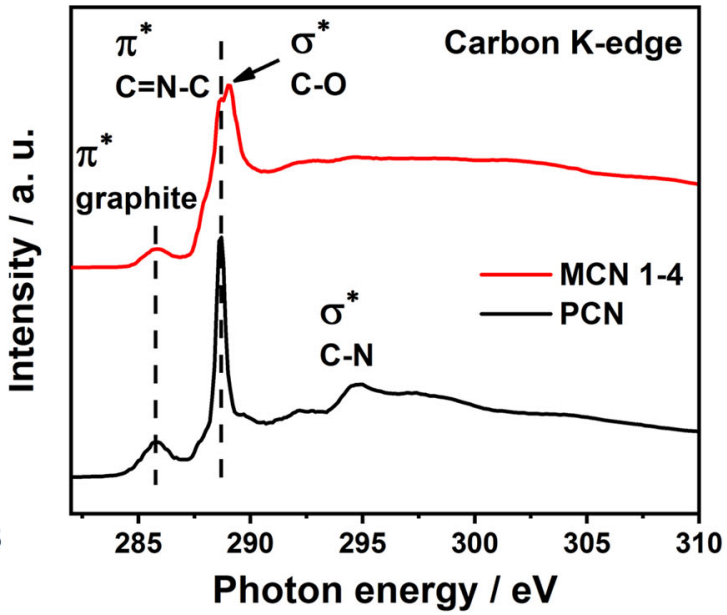

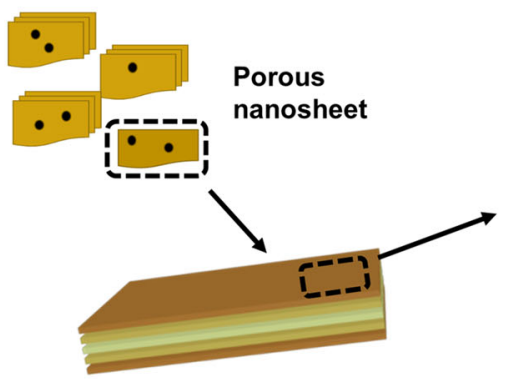

Inconsistent element distribution
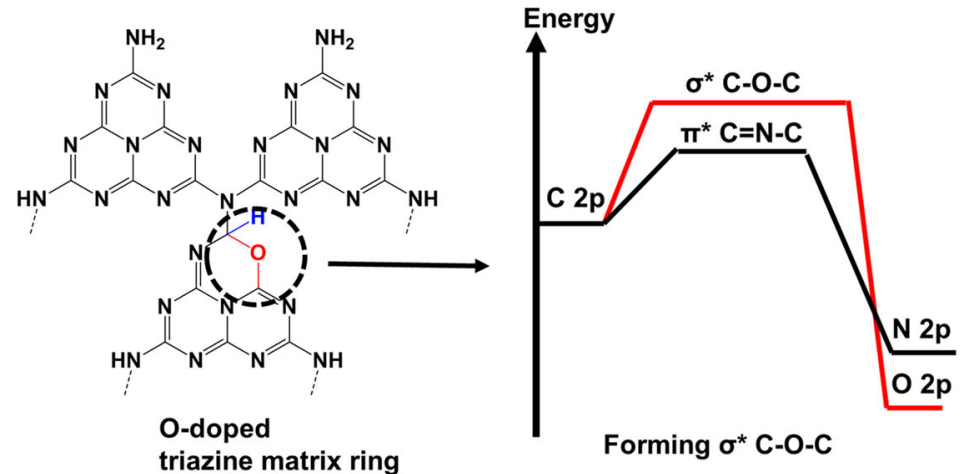

Forming $\sigma^{*} \mathrm{C}-\mathrm{O}-\mathrm{C}$

Fig. 6 NEXAFS characterization and schematic from structure to atomic orbital description of PCN and MCN1-4. NEXAFS spectra of PCN and MCN1-4 at the $\mathbf{a}$ nitrogen K-edge and $\mathbf{b}$ carbon K-edge. $\mathbf{c}$ Schematic description of covalent bonding in terms of atomic orbitals.

a

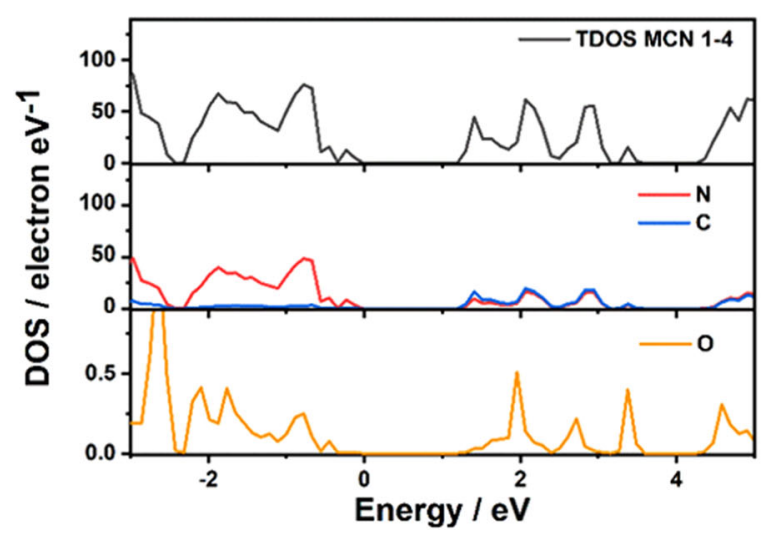

b

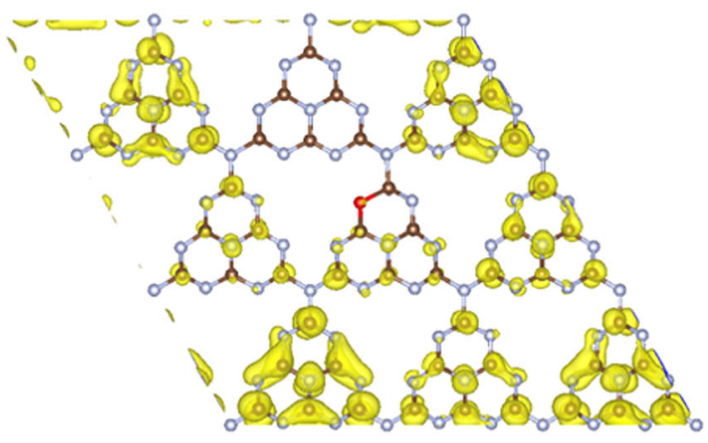

Fig. 7 Computational calculation of MCN1-4. a TDOS and PDOS of MCN1-4 and $\mathbf{b}$ the charge density of MCN1-4 derived from DOS at 1.33 eV. The Fermi level is set to zero.

density of states (PDOS) spectra of MCN1-4. It can be seen that the $\mathrm{O}$ atom starts to contribute to the conduction band from $1.31 \mathrm{eV}$ near the conduction band edge $(1.29 \mathrm{eV})$, and then reaches the maximum contribution at $1.95 \mathrm{eV}$. To further clarify the contribution of the $\sigma^{*}{ }_{\mathrm{C}-\mathrm{O}}$ in $\mathrm{MCN1}-4$, we present charge density of MCN1-4 the orbital information associated with the selected states in the TDOS of MCN1-4 (see Supplementary Fig. 26). As shown in Fig. 7b, a small amount of charge density can be observed on $\mathrm{O}$ atoms at $1.33 \mathrm{eV}$, which is only $0.05 \mathrm{eV}$ higher than LUMO. The results demonstrate that the photogenerated electrons can be easily transferred to $\sigma^{*}{ }_{\mathrm{C}-\mathrm{O}}$, which is consistent with the experimental results. 


\section{Discussion}

To achieve a full spectrum response and a high activity, in addition to the upconversion properties of the carbon nitride due to defects, it is required that the lifetime of the photoexcited carriers should be sufficiently long. MCN1-4 has three features that result in a long photoexcited carrier lifetime: 1 . O doped into the $\mathrm{N}$ position of the $\mathrm{C}=\mathrm{N}-\mathrm{C}$ moiety in the triazine matrix ring to form a $\sigma^{*} \mathrm{C}-\mathrm{O}$ orbital in conduction band and thus greatly inhibit the recombination of photoexcited electron-hole pairs; 2 . a nanosheet morphology $(3.5 \mathrm{~nm})$ that provides not only a short distance for charge transfer from the interior of the material to the reaction site; 3 . a gradual increase in the $\mathrm{C}$ content from the inside of the material to the surface, facilitating charge transfer from the inside to the surface (Fig. $6 \mathrm{c}$ ). The latest reports on the development of infrared response photocatalysts have several shortcomings. For example, the photocatalysts achieve infrared light response at the expense of the activity under high-energy light irradiation; the photocatalysts must be compounded with other photocatalysts due to their low redox capacity. We believe that our strategy will open a brand-new approach for designing carbon nitride and other photocatalysts that can convert fullspectrum solar energy into chemical energy more efficiently. In addition, non-toxic $\mathrm{C}_{3} \mathrm{~N}_{4}$ with high efficiency under infrared light provides a promising candidate for phototherapy.

\section{Methods}

Materials. Melamine (Aladdin, 99\%), Cyanuric acid (Aladdin, 98\%), Triethanolamine (Aladdin, AR-98\%), $\mathrm{TiO}_{2}$ (degussa, P25), $\mathrm{TiO}_{2}$ (anatase, Macklin, 99.8\%, $60 \mathrm{~nm}$ ) and Hydrochloroplatinic acid (Alfa Aesar, ACS-99.95\%, Pt 37.5\%) were used as starting materials without further treatment. Deionized water (18.5 $\mathrm{M} \Omega$, EREE water systems) was used in the whole experiments.

Preparation of $\mathbf{P C N}$ and $\mathbf{M C N} \mathbf{x}-\mathbf{y}$. Bulk $\mathrm{C}_{3} \mathrm{~N}_{4}$ (polymeric carbon nitride, PCN) was synthesized by heating $3 \mathrm{~g}$ of melamine at $550{ }^{\circ} \mathrm{C}$ for $4 \mathrm{~h}$, the heating rate is $5^{\circ} \mathrm{C} \min ^{-1}$.

Firstly, MCx-y was prepared by a facile hydrothermal treatment. Five grams of melamine and cyanuric acid composite (melamine/cyanuric acid are 2.5/2.5, 2/3, $1.5 / 3.5$ and $1 / 4$ weight ratio) was dispersed in $50 \mathrm{ml}$ water by $15 \mathrm{~min}$ sonication and $15 \mathrm{~min}$ stirring. The suspension liquid was transferred into a $100 \mathrm{ml}$ Telflon-lined autoclave and then heated at in an oven $150^{\circ} \mathrm{C}$ for $6 \mathrm{~h}$. After filtration and evaporation, a white powder was obtained, which was referred to as MCx-y (x and $y$ are respectively denote as the added weight of melamine and cyanuric acid).

Then 3 grams of white powder was placed in an alumina crucible with a cover and heated to $550{ }^{\circ} \mathrm{C}$ in muffle furnace at a heating rate of ca. $5{ }^{\circ} \mathrm{C} \mathrm{min}-1$. After heating at $550^{\circ} \mathrm{C}$ for $4 \mathrm{~h}, \mathrm{MCNx}$-y was obtained. It is worth noting that the muffle furnace used in here should has a good thermal insulation.

Photocatalytic activity under infrared light irradiation. Fifty mg of sample was dispersed in $100 \mathrm{ml}$ water $\left(10 \mathrm{vol} \%\right.$ of TEOA, and $\mathrm{H}_{2} \mathrm{PtCl}_{6}$ of $3 \mathrm{wt} \% \mathrm{Pt}$ to the sample) for $10 \mathrm{~min}$ by sonication. The solution was transferred to the photocatalysis reactor, and vacuumed with stirred. Xe lamp (CEAULIGHT, CELHXF300, $300 \mathrm{~W}$ ) with 420 cut-off filter (CEAULIGHT, CEL-UVIRCUT420) was used to irradiate the solution for $3 \mathrm{~h}$ (for Pt deposition). Subsequently, 800 cut-off filter (CEAULIGHT, CEL-UVIRCUT800) was used, the average light intensity was $24.4 \mathrm{~mW} \mathrm{~cm}^{-2}$. The amounts of generated hydrogen were monitored by gas chromatography (TCD, CEAULIGHT, GC-7920) every 30 min. Ultrapure $\mathrm{N}_{2}$ was used as the carrier gas. The reaction temperature was maintained $285 \mathrm{~K}$ by cycle water, unless otherwise noted.

Photocatalytic activity under visible light irradiation. Ten $\mathrm{mg}$ of sample was dispersed in $100 \mathrm{ml}$ water $\left(10\right.$ vol\% of TEOA, and $\mathrm{H}_{2} \mathrm{PtCl}_{6}$ of $3 \mathrm{wt} \% \mathrm{Pt}$ to the sample) for $10 \mathrm{~min}$ by sonication. The solution was transferred to the photocatalysis reactor, and vacuumed with stirred. A $300 \mathrm{~W}$ Xe lamp with 420 cut-off filter was used as the light source (the light intensity of the high position in the middle level of the liquid was $100 \mathrm{~mW} \mathrm{~cm}^{-2}$ ).

Photocatalytic activity under AM 1.5G irradiation. The same procedure was used as that under visible light, except that Xe lamp (300 W) with AM 1.5G filter (CEAULIGHT, CEL-AM1.5) was used as the light source (the light intensity of the high position in the middle level of the liquid was $100 \mathrm{~mW} \mathrm{~cm}^{-2}$ ).

Computational details. We investigated the DOS and PDOS of samples by using the Vienna Ab Initio Simulation Package (VASP) ${ }^{37}$ based on density functional theory (DFT). A large $3 \times 3$ supercell with perpendicular vacuum of $15 \AA$ was used to eliminate the spurious interaction from the periodic. The generalized gradient approximation (GGA) as proposed by Perdew, Burke, and Ernzerhof (PBE) ${ }^{38}$ considered the exchange-correlation functional, as well as the projector augmented wave (PAW) potentials. The lattice constants were set to $\mathrm{a}=\mathrm{b}=6.8 \AA$, all atoms were relaxed until the total energy converged to $10^{-5} \mathrm{eV}$ and the residual force on each atom was less than $0.01 \mathrm{eV}^{-1}$. The plane-wave kinetic-energy cutoff was $450 \mathrm{eV}$ and the grid mesh was $2 \times 2 \times 1$.

\section{Data availability}

The authors declare that obtained and analyzed data are contained in the paper and the Supplementary Information, and are available from the corresponding author on reasonable request.

Received: 24 June 2020; Accepted: 28 October 2020; Published online: 25 November 2020

\section{References}

1. Hisatomi, T., Kubota, J. \& Domen, K. Recent advances in semiconductors for photocatalytic and photoelectrochemical water splitting. Chem. Soc. Rev. 43, 7520-7535 (2014).

2. Wang, Z., Li, C. \& Domen, K. Recent developments in heterogeneous photocatalysts for solar-driven overall water splitting. Chem. Soc. Rev. 48 , 2109-2125 (2019).

3. Hernández-Alonso, M. D., Fresno, F., Suárez, S. \& Coronado, J. M. Development of alternative photocatalysts to $\mathrm{TiO}_{2}$ : challenges and opportunities. Energy Environ. Sci. 2, 1231-1257 (2009).

4. Maeda, K. \& Domen, K. Photocatalytic water splitting: recent progress and future challenges. J. Phys. Chem. Lett. 1, 2655-2661 (2010).

5. Yang, M.-Q., Gao, M., Hong, M. \& Ho, G. W. Visible-to-NIR photon harvesting: progressive engineering of catalysts for solar-powered environmental purification and fuel production. Adv. Mater. 30, 1802894 (2018).

6. Rahman, M. Z., Kwong, C. W., Davey, K. \& Qiao, S. Z. 2D phosphorene as a water splitting photocatalyst: fundamentals to applications. Energy Environ. Sci. 9, 709 (2016).

7. Jiang, J. et al. Synthesis of visible and near infrared light sensitive amorphous titania for photocatalytic hydrogen evolution. Green Chem 18, 2056 (2016).

8. Wang, X. et al. A metal-free polymeric photocatalyst for hydrogen production from water under visible light. Nat. Mater. 8, 76-80 (2009).

9. Zhao, F. et al. Supramolecular quantum dots as biodegradable nano-probes for upconversion-enabled bioimaging. Chem. Commun. 51, 13201-13204 (2015).

10. Zhang, $X$. et al. Single-layered graphitic- $\mathrm{C}_{3} \mathrm{~N}_{4}$ quantum dots for two-photon fluorescence imaging of cellular nucleus. Adv. Mater. 26, 4438 (2014).

11. Liu, J. et al. Metal-free efficient photocatalyst for stable visible water splitting via a two-electron pathway. Science 347, 970-974 (2015).

12. Zhang, J.-W. et al. Oxygen-doped nanoporous carbon nitride via water-based homogeneous supramolecular assembly for photocatalytic hydrogen evolution. Appl. Catal. B 221, 9-16 (2018).

13. Zhen, W. et al. Efficient visible-light-driven selective oxygen reduction to hydrogen peroxide by oxygen-enriched graphitic carbon nitride polymers. Energy Environ. Sci. 11, 2581 (2018).

14. Wang, Y. et al. Linker-controlled polymeric photocatalyst for highly efficient hydrogen evolution from water. Energy Environ. Sci. 10, 1643-1651 (2017).

15. Wei, F. et al. Oxygen self-doped g- $\mathrm{C}_{3} \mathrm{~N}_{4}$ with tunable electronic band structure for unprecedentedly enhanced photocatalytic performance. Nanoscale 10, 4515-4522 (2018).

16. $\mathrm{Yu}, \mathrm{Y}$. et al. Surface engineering for extremely enhanced charge separation and photocatalytic hydrogen evolution on $g-\mathrm{C}_{3} \mathrm{~N}_{4}$. Adv. Mater. 30, 1705060 (2018).

17. Ou, H. et al. Tri-s-triazine-based crystalline carbon nitride nanosheets for an improved hydrogen evolution. Adv. Mater. 29, 1700008 (2017).

18. Jürgens, B. et al. Melem (2,5,8-triamino-tri-s-triazine), an important intermediate during condensation of melamine rings to graphitic carbon nitride: synthesis, structure determination by X-ray powder diffractometry, solid-state NMR, and theoretical studies. J. Am. Chem. Soc. 125, 10288-10300 (2003).

19. Zhang, Q. et al. A photocatalytic degradation strategy of PPCPs by a heptazine-based CN organic polymer (OCN) under visible light. Environ. SciNano 5, 2325-2336 (2018).

20. Jin, Z. et al. Hydrogen bonds in heterojunction photocatalysts for efficient charge transfer. Appl. Catal. B 234, 198-205 (2018). 
21. Jun, Y.-S. et al. From melamine-cyanuric acid supramolecular aggregates to carbon nitride hollow spheres. Adv. Funct. Mater. 23, 3661-3667 (2013).

22. Shalom, M., Inal, S., Fettkenhauer, C., Neher, D. \& Antonietti, M. Improving carbon nitride photocatalysis by supramolecular preorganization of monomers. J. Am. Chem. Soc. 135, 7118-7121 (2013).

23. Haase, M. \& Schafer, H. Upconverting nanoparticles. Angew. Chem., Int. Ed. 50, 5808-5829 (2011).

24. Ren, C. et al. A near-infrared I emissive dye: toward the application of saturable absorber and multiphoton fluorescence microscopy in the deeptissue imaging window. Chem. Comm 55, 5111-5114 (2019).

25. Lau, V. W.-h. et al. Rational design of carbon nitride photocatalysts by identification of cyanamide defects as catalytically relevant sites. Nat. Commun. 7, 12165 (2016)

26. Kudo, A. \& Miseki, Y. Heterogeneous photocatalyst materials for water splitting. Chem. Soc. Rev. 38, 253-278 (2009).

27. Huang, S. et al. Non-precious molybdenum nanospheres as a novel cocatalyst for full-spectrum-driven photocatalytic $\mathrm{CO}_{2}$ reforming to $\mathrm{CH}_{4}$. J. Hazard. Mater. 393, 122324-122330 (2020).

28. Yuan, J. et al. Crystallization, cyanamide defect and ion induction of carbon nitride: exciton polarization dissociation, charge transfer and surface electron density for enhanced hydrogen evolution. Appl. Catal. B 251, 206-212 (2019).

29. Godin, R., Wang, Y., Zwijnenburg, M. A., Tang, J. \& Durrant, J. R. Timeresolved spectroscopic investigation of charge trapping in carbon nitrides photocatalysts for hydrogen generation. J. Am. Chem. Soc. 139, 5216-5224 (2017).

30. Corp, K. L. \& Schlenker, C. W. Ultrafast spectroscopy reveals electron-transfer cascade that improves hydrogen evolution with carbon nitride photocatalysts. J. Am. Chem. Soc. 139, 7904-7912 (2017).

31. Liang, L. et al. Infrared light-driven $\mathrm{CO}_{2}$ overall splitting at room temperature. Joule 2, 1004-1016 (2018).

32. Wang, $\mathrm{H}$. et al. Oxygen-vacancy-mediated exciton dissociation in $\mathrm{BiOBr}$ for boosting charge-carrier-involved molecular oxygen activation. J. Am. Chem. Soc. 140, 1760-1766 (2018).

33. Zheng, Y. et al. Hydrogen evolution by a metal-free electrocatalyst. Nat. Commun. 5, 3783 (2014).

34. Zhang, G. et al. Tailoring the grain boundary chemistry of polymeric carbon nitride for enhanced solar hydrogen production and $\mathrm{CO}_{2}$ reduction. Angew. Chem., Int. Ed. 58, 3433-3437 (2019).

35. Kuznetsova, A. et al. Oxygen-containing functional groups on single-wall carbon nanotubes: NEXAFS and vibrational spectroscopic studies. J. Am. Chem. Soc. 123, 10699-10704 (2001).

36. Atkins, P., Jones, L. \& aLaverman, L. Chemical Principles. The Quest for Insight, $6^{\text {th }}$ ed. 2005, (W.H. Freeman \& Company Press).

37. Kress, G. \& Furthmülle, J. Efficiency of ab-initio total energy calculations for metals and semiconductors using a plane-wave basis set. Comput. Mater. Sci. 6, 15-50 (1996).

38. Kress, G. \& Furthmülle, J. Efficiency iterative schemes for ab initio totalenergy calculations using a plane-wave basis set. Phys. Rev. B 54, 11169-11186 (1996).

\section{Acknowledgements}

This work was supported by the Shenzhen Science and Technology Project under Grant Nos. JCYJ20170412105400428 and JCYJ20180507182246321, the Shenzhen Peacock Technological Innovation Project under Grant No. KQJSCX20170727101208249, the National Natural Science Foundation of China under Grant No. 21805191. Near Edge X-ray Absorption Fine Structure (NEXAFS) were carried out at the Catalysis and Surface Science Endstation at the BL11U beamline in the National Synchrotron Radiation Laboratory (NSRL) in Hefei, China. The authors thank the technical support from The Photonics Centre of Shenzhen University.

\section{Author contributions}

Z.J. conceived the idea and conducted the experiments. X.J. conducted the TAS measurement. Q.Z. measured and analyzed NEXAFS. Z.J., S.H., and L.Z. discussed the experiment detail. T.H. conducted open-aperture the Z-scan measurement. L.H. conducted computational calculation. Y.Z., H.Z., and S.R. supervised the experimental work. Z.J., T.O., and Y. Z. discussed the results and wrote the paper with contributions from the other authors.

\section{Competing interests}

The authors declare no competing interests.

\section{Additional information}

Supplementary information is available for this paper at https://doi.org/10.1038/s43246020-00093-z.

Correspondence and requests for materials should be addressed to Y.-J.Z.

Peer review information Primary handling editor: John Plummer

Reprints and permission information is available at http://www.nature.com/reprints

Publisher's note Springer Nature remains neutral with regard to jurisdictional claims in published maps and institutional affiliations.

(c) (i) Open Access This article is licensed under a Creative Commons Attribution 4.0 International License, which permits use, sharing, adaptation, distribution and reproduction in any medium or format, as long as you give appropriate credit to the original author(s) and the source, provide a link to the Creative Commons license, and indicate if changes were made. The images or other third party material in this article are included in the article's Creative Commons license, unless indicated otherwise in a credit line to the material. If material is not included in the article's Creative Commons license and your intended use is not permitted by statutory regulation or exceeds the permitted use, you will need to obtain permission directly from the copyright holder. To view a copy of this license, visit http://creativecommons.org/ licenses/by/4.0/.

(C) The Author(s) 2020 